\title{
UM RELATO DE EXPERIÊNCIA BASEADO EM ASPECTOS MOTORES E COGNITIVOS DE UMA TURMA DE SEGUNDO ANO DO ENSINO FUNDAMENTAL DE UMA ESCOLA PÚBLICA
}

Mariele Santayana de Souza, Universidade Federal do Rio Grande do Sul - UFRGS, Porto Alegre, Rio Grande do Sul - Brasil

\section{RESUMO}

O objetivo desse relato de experiência é refletir sobre as vivências de uma aluna no estágio docência em Educação Física. O estágio foi realizado com crianças de uma turma de $2^{\circ}$ ano do ensino fundamental de uma escola pública do Sul do Brasil. O relato perpassa pelas observações do desenvolvimento motor e cognitivo dos alunos ao longo das aulas em um semestre e as dificuldades encontradas pelo professor em formação para a realização do estágio. O relato é baseado em um diário de campo preenchido ao final de cada aula e nas observações diárias.

Palavras-Chave: Habilidades motoras; Educação Física; Desenvolvimento cognitivo.

\section{AN EXPERIENCE REPORT BASED ON MOTOR AND COGNITIVE ASPECTS OF A CLASS OF SECOND YEAR OF ELEMENTARY SCHOOL IN A PUBLIC SCHOOL}

\begin{abstract}
The objective of this experience' report is to reflect about the practices of a student teaching internship in Physical Education. The internship was conducted with a second grade group of student at a elementary' public school in the southern of Brazil. The report unfolds the observations of students' motor and cognitive development along of a one semester of classes and the difficulties faced by the teacher-in-training in the implementation of the internship. The report is based on a field' diary completed at the end of each class and in the daily observations.
\end{abstract}

Key-Words: Motor skills; Physical Education; Cognitive development.

UN INFORME DE LA EXPERIENCIA BASADA EN ASPECTOS MOTORES Y COGNITIVOS DE UNA CLASE DE SEGUNDO AÑO DE LA ESCUELA PRIMARIA EN UNA ESCUELA PÚBLICA

Conexões: revista da Faculdade de Educação Física da UNICAMP, Campinas, v. 13, n. 2, p. 206-218, abr./jun. 2015. ISSN: 1983-9030 


\section{RESUMEN}

El objetivo de este informe es reflexionar sobre las experiências de un estudiante de prácticas de enseñanza en Educación Física. La capacitación se llevó acabo con niños de una clase de segundo año, de la educación primaria, en una escuela pública en el sur de Brasil. La historia pasa a través de las observaciones del desarrollo motor y cognitivo de los estudiantes durante la clase en un semestre y las dificultades encontradas por el professor en formación en su etapa de realización. El informe se basa en un diário realizado al final de cada clase, además de las observaciones diarias.

Palavras-Clave: Destreza motora; Educación Físico; Desarollo cognitivo. 


\section{INTRODUÇÃO}

O desenvolvimento humano é composto por diferentes domínios - motor, cognitivo e social/afetivo - que são dependentes; atraso em um dos domínios pode resultar em dificuldades de desenvolver potencialmente os outros domínios. ${ }^{1-2}$ As interações com os aspectos ambientais que podem influenciar o desenvolvimento da crianças no meio em que ela está inserida são fundamentais para o desenvolvimento pleno dos diferentes domínios. ${ }^{1}$ A infância é um período importante para o aprendizado e aquisição de hábitos que serão mantidos ao longo da vida, ${ }^{1}$ dessa forma proporcionar experiências positivas e significativas para crianças é uma forma de incentivar hábitos saudáveis, como os de práticas motoras.

O desempenho motor é fundamental para a inserção das crianças em brincadeiras e atividades do dia a dia, tendo em vista que as habilidades motoras fundamentais são prérequisito para o aprendizado de habilidades mais complexas utilizadas na vida diária, em atividades rítmicas, esportivas e recreativas. ${ }^{1,3-4}$ Além disso, a preocupação com a aquisição de padrões motores adequados para a faixa etária está relacionada à participação e manutenção de um estilo ativo, ${ }^{5}$ o qual está relacionado a prevenção de uma série de doenças relacionadas ao sedentarismo. ${ }^{6}$ Estudos tem mostrado associação positiva entre o desempenho motor e os níveis de atividade física em criança. ${ }^{7-8}$ Sendo assim ao demonstrar competência motora mais elevada as crianças teriam mais oportunidades de participar de atividades ativas, uma vez que dominando um maior número de habilidades elas conseguem optar entre diferentes atividades e se inserir em diferentes práticas esportivas e de lazer.

Crianças passam grande período do dia em brincadeiras e atividades lúdicas ativas, ${ }^{9}$ nas quais exploram diferentes movimentos. No entanto, somente atividades livres não auxiliam o aprendizado de uma variedade de habilidades motoras fundamentais, ${ }^{10}$ sendo necessário períodos de atividades estruturadas para o aprendizado das habilidades que serão básicas para o aprendizado futuro de habilidades mais complexas. ${ }^{9}$ A partir de atividades Conexões: revista da Faculdade de Educação Física da UNICAMP, Campinas, v. 13, n. 2, p. 206-218, abr./jun. 2015. ISSN: $1983-9030$ 
estruturadas, como atividades em estações e jogos, as crianças desenvolvem as habilidades motoras fundamentais ${ }^{3}$ e também passam a criar estratégias individuais e em grupo para atingir os objetivos dos jogos, assim podendo influenciar no desenvolvimento motor e cognitivo. Na escola, principalmente as aulas de educação física são responsáveis por promover atividades lúdicas estruturadas adequadas a cada faixa etária, assim facilitando o desenvolvimento adequado dos alunos. Portanto, esse relato de experiência tem por objetivo descrever as mudanças em aspectos motores e cognitivos percebidos em um estágio no ensino fundamental.

\section{MÉTODO}

Realizamos um relato de experiência de um estágio de Educação Física realizado em um segundo ano do ensino fundamental de uma escola estadual de uma cidade do Sul do Brasil. Os relatos reportados foram baseados em observações ao longo do semestre de estágio e em um diário de campo, o qual era preenchido ao final de cada aula ressaltando os aspectos que mais ficaram evidentes em cada aula a respeito de aspectos motores e cognitivos. O relato dos aspectos motores são baseados no estágio das habilidades motoras fundamentais proposto por Gallahue e Ozmun, ${ }^{1}$ enquanto o relato dos aspectos cognitivos são baseados nos diferentes períodos de desenvolvimento propostos por Piaget e descritos por Gallahue e Ozmun ${ }^{1}$ e Payne e Isaacs. ${ }^{2}$

\section{Caracterização do ambiente e da turma}

O espaço destinado as aulas era uma quadra poliesportiva, uma quadra de voleibol e um pequeno espaço coberto. As quadras não possuem marcações e não havia uma delimitação física entre elas. O piso do espaço aberto era irregular, dificultando a execução de algumas habilidades. Mesmo sem divisão física entre as quadras, havia mais de uma turma tendo aula de Educação Física no mesmo horário. Em relação aos materiais, a escola disponibilizou colchonetes, os outros materiais, como bolas de diferentes modalidades, tamanhos e pesos (ex.: futebol, basquete, jornal), cordas, jogo de boliche, jornal, balão, fita crepe, boliche, arcos, giz, lenços e garrafas pet foram fornecidos pelos responsáveis pelo estágio. $\mathrm{O}$ estágio foi realizado em uma turma do $2^{\circ}$ do ensino fundamental. $\mathrm{O}$ número de alunos que frequentavam a escola regularmente era de aproximadamente 16 crianças $(8$ Conexões: revista da Faculdade de Educação Física da UNICAMP, Campinas, v. 13, n. 2, p. 206-218, abr./jun. 2015. ISSN: $1983-9030$ 
meninos e 8 meninas). A idade variava de 7 a 11 anos, predominando crianças de 8 e 9 anos.

\section{RESULTADOS E DISCUSSÃO}

A metodologia e conteúdos das aulas foi escolhida a partir do modelo de Gallahue e Ozmun ${ }^{1}$ que afirmam que o desenvolvimento motor é composto por estágios sequenciais. Dessa forma, é fundamental o aprendizado de variadas habilidades motoras fundamentais para o envolvimento em atividades mais complexas, assim facilitando que a criança permaneça fisicamente ativa ao longo da vida. ${ }^{1,3}$ Para mediar o desenvolvimento motor e cognitivo dos alunos as aulas eram compostas por estações, visando: o aprendizado de habilidades motoras fundamentais, jogos adaptados (pré-desportivos); desenvolvimento da percepção espaço temporal; reconhecimento de inclusão de regras; aumento da cooperação entre os alunos; participação na elaboração de estratégias individuais e em grupos para a resolução dos problemas impostos pelos jogos. Também foram desenvolvidas atividades rítmicas e de esquema corporal.

A escolha dos tipos de atividades e formato das aulas se deu em função de duas aulas diagnóstico em que percebemos as dificuldades de execução de habilidades motoras fundamentais de locomoção (ex.: corrida lateral e saltos) e de controle de objeto (ex.: quicar e arremessar) e dificuldades de organização em jogos com regras complexas e com muitas crianças. Para isso, as aulas eram divididas em 3 momentos: a) parte inicial (aproximadamente 5 minutos) em que era feito a chamada, lembranças da aula anterior, retomada de combinações e atividades de aquecimento (ex.: pega-pega); b) parte principal (aproximadamente 25 minutos) em que eram desenvolvidas as atividades em estações e jogos adaptados; e c) parte final (aproximadamente 5 minutos) em que eram realizadas atividades de volta à calma e retomada dos momentos principais da aula. Todos conteúdos foram desenvolvidos de forma lúdica e adequada ao desenvolvimento. O tempo total disponível para as aulas era de cerca de 45 minutos, no entanto eram utilizados cerca de 35 minutos em virtude de que era o primeiro período escolar e, conforme protocolo das 
crianças com a professora de sala, eles chegavam na escola e iam até a sala de aula para guardar os materiais.

\section{Desenvolvimento motor}

O desenvolvimento motor foi observado semanalmente e ao final foram elaboradas 2 aulas com estações com todas habilidades trabalhadas ao longo do período de aulas. As observações foram baseadas nas características da fase fundamental, a qual é dividida em estágios inicial, elementar e maduro proposta pro Gallahue e Ozmun. ${ }^{1}$ A literatura sugere que crianças tem capacidade para atingir o estágio maduro aos 6/7 anos. ${ }^{1}$ Dessa forma, nossas observações perpassam pela crença de que nossos alunos deveriam já estar ou ter atingido o padrão maduro das habilidades motoras trabalhadas.

Desde as primeiras aulas percebemos que a maioria dos alunos apresentavam dificuldades de executar as habilidades em um padrão maduro. As dificuldades foram detectadas no(a) 1) corrida lateral em que as crianças não ficavam de frente para o local de término da tarefa; 2) quicar uma bola tanto parado quanto em movimento em que as crianças não conseguiam executar muitos quiques; 3) salto horizontal, em que tinham dificuldades de pousar com ambos os pés simultaneamente; 4) rolar e arremessar a bola em que tinham dificuldades de executar com o braço oposto da perna que vai a frente; e 5) salto com um pé em que tinham dificuldades de manter o equilíbrio em saltos consecutivos e de realizar o pêndulo. Todas características motoras observadas nas crianças evidenciam desenvolvimento nos estágios inicial ou elementar.

Ao final do estágio, as mudanças motoras que mais percebemos foram no salto em um pé, na corrida lateral, no quicar, no salto horizontal e no arremesso. No salto com um pé notamos que os movimentos no já eram mais seguros e eficientes, a medida que eles conseguiam permanecer mais tempo saltando em um pé só quando comparado ao início das aulas. Algumas crianças já estavam fazendo o pêndulo ou iniciando o movimento pendular, que é essencial para a propulsão de força nessa habilidade e característica do padrão maduro do salto em um pé. Na corrida lateral, as crianças já ficavam de lado durante todo movimento, sem rotar o tronco a ponto de o peito virar para frente, o que é 
essencial para a realização da corrida lateral. No quicar, talvez tenham ocorrido os maiores ganhos, uma vez a maioria já conseguia quicar a bola parado e em movimento. Quando em movimento, elas ainda não tinham muito controle da altura do quique, uma vez que a bola se deslocava em diferentes alturas, no entanto elas já conseguiam se deslocar quicando a bola sem perder o controle. No salto horizontal, a maioria passou a aterrissar com os dois pés simultaneamente, no entanto ainda não faziam o movimento em um padrão maduro devido ao pouco ou nenhum impulso dos braços na fase de preparação. No arremesso a maioria dos aspectos encontravam-se em um padrão maduro, no entanto, não havia o acompanhamento contralateral após soltar a bola, ou seja, as crianças não davam continuidade ao movimento. O rolar a bola talvez tenha sido a habilidade que mais encontramos diferenças entre as crianças, uma vez que umas passaram a fazer de maneira contra lateral, no entanto alguns colocavam a bola no chão e empurravam, alguns encostavam um ou os dois joelhos no chão e ainda tinha os que não davam passo a frente e somente afastavam as pernas e flexionavam o tronco para rolar.

Na literatura é ressaltado que a aquisição de habilidades motoras em um padrão maduro depende das oportunidades para a prática das habilidades, ${ }^{3}$ bem como acesso e incentivo para a prática física, ${ }^{11}$ fatores que procuramos implementar ao longo da nossa prática. $\mathrm{O}$ modelo de Newell citado por Haywood e Getchell, ${ }^{12}$ Gallhaue e Ozmun ${ }^{1}$ e Payne e Isaacs ${ }^{2}$ sugere que o movimento é resultado da interação entre o indivíduo, o ambiente e a tarefa. Dessa maneira, o movimento é influenciado pelos fatores biológicos do indivíduo, pelas experiências e aprendizagens e pelos fatores mecânicos e físicos da tarefa. Ao iniciar as aulas, as crianças afirmaram que nunca haviam tido aulas de educação física e que não realizavam práticas físicas fora da escola. Tendo em vista as mudanças ocorridas em um curto período de aproximadamente três meses (tempo de aulas ministradas na escola durante o período do estágio) podemos afirmar que as dificuldades encontradas pelos alunos nas habilidades motoras se dava principalmente pela falta de experiência em atividades estruturadas adequadas a faixa etária. Os ganhos em um período de tempo curto ressaltam a importância de mediar atividades estruturadas adequadas ao desenvolvimento dos alunos para auxiliar a aquisição de variadas habilidades motoras, o que é essencial para a manutenção de um estilo de vida ativo e saudável ao longo da vida.

Conexões: revista da Faculdade de Educação Física da UNICAMP, Campinas, v. 13, n. 2, p. 206-218, abr./jun. 2015. ISSN: $1983-9030$ 


\section{Desenvolvimento cognitivo}

A avaliação do desenvolvimento cognitivo se deu a partir do modelo de Piaget citado por Gallahue e Ozmun ${ }^{1}$ e Payne e Isaacs. ${ }^{2} \mathrm{O}$ modelo é baseado em uma série de estágios que descrevem as capacidades cognitivas e de pensamento de crianças em diferentes faixas etárias. Para esse modelo, as crianças a partir dos 7 anos de idade devem evidenciar características de pensamento operacional concreto, o qual é observável pelo direcionamento da atenção da criança em vários aspectos do que se está fazendo ou observando. ${ }^{2}$ Os autores também afirmam que a criança tem maior capacidade de imaginar o que está sendo falado ou pensado, possibilitando a formulação de estratégias em jogos. Para avaliar o desenvolvimento cognitivo observamos durante o período de aulas as atitudes das crianças em relação as atividades, aos colegas e professores.

Os alunos formulavam estratégias tanto para a sua equipe, quanto para neutralizar o adversário em diversas atividades. Por exemplo, no pega-pega corrente as crianças formulavam estratégias para pegar os outros conforme as ações dos colegas. No futebol adaptado eles também formulavam estratégias para atacar e defender seu gol. Nessa perspectiva, para realizara atividade além da criação de estratégias eles tinham de direcionar a atenção para diversos aspectos da atividade, como as ações dos colegas.

Segundo a teoria de Piaget, as crianças por volta dos 7 anos são menos egocêntricas e o pensamento é mais lógico. ${ }^{1-2}$ As crianças nessa idade entendem melhor conceitos espaciais, causalidade, categorização, raciocínio indutivo e dedutivo, conservação e números. ${ }^{13}$ Ao desenvolver atividades mais complexas, as quais exigiam atenção, observação e trabalho em grupo, percebíamos algumas crianças ainda com padrão egocêntrico e com algumas dificuldades de noções espaciais. Um exemplo dessa situação é a brincadeira do "Coelhinho sai da Toca" em que muitas crianças não queriam sair de sua toca e ficavam bravas quando algum colega tentava entrar na sua toca. Outro exemplo, é a brincadeira do "Rouba Rabos", em que cada criança ficava com um papel preso na calça e o objetivo era pegar o papel dos colegas e cuidar para que ninguém pagasse o seu. Da mesma forma algumas crianças choravam e ficavam tristes quando seus colegas roubavam seus rabos. 
Mesmo que a brincadeira fosse conseguir o máximo de rabos possíveis, elas estavam mais preocupadas em manter o seus rabos do que conseguir rabos novos. Essas dificuldades cognitivas foram rapidamente superadas, tendo em vista que ao longo das aulas através das experiências vivenciadas e de conversas constantes entre estagiários e alunos explicando os objetivos das atividades as crianças passaram a conseguir executar de forma satisfatória as atividades que exigiam pensamento mais complexo.

$\mathrm{Na}$ última aula fizemos uma auto avaliação com as crianças, na qual elas tinham diversas habilidades e deveriam marcar como avaliavam sua competência (sabe/consegue fazer, não está muito segura se consegue realizar de maneira competente e não sabe fazer) fundamentado nas avaliações propostas por Valentini e Toigo. ${ }^{3} \mathrm{Na}$ auto avaliação percebemos outros aspectos relacionados ao desenvolvimento cognitivo, que é a autopercepção. Comparando as percepções das crianças e os padrões motores que analisamos durante as aulas, concluímos que elas não eram precisas em suas avaliações, uma vez que geralmente percebiam-se mais competentes do que realmente eram. $\mathrm{Na}$ literatura encontramos que crianças pequenas geralmente percebem-se mais competente do que realmente são ${ }^{14}$ e com o passar dos anos vão tornando-se mais realistas em relação a sua competência. ${ }^{15}$

Essas mudanças na auto percepção estão relacionadas tanto ao desenvolvimento $\operatorname{cognitivo~}^{16}$ - responsável por maior precisão nas avaliações - e ao meio social da criança. $^{15}$ Crianças menores convivem mais com adultos significativos, sendo influenciadas pela opinião dessas pessoas. ${ }^{14}$ Com o passar dos anos as crianças passam a ter mais experiências e há maior valorização do grupo de amigos e da opinião deles. ${ }^{14} \mathrm{Com}$ essa mudança nas fontes de informação de competência associada ao desenvolvimento cognitivo e as experiências a criança passa a fazer comparações da sua competência com a de seus pares criando padrões de competência, o que está associado a diminuição da percepção de suas habilidades. ${ }^{17}$

Estudos nacionais tem verificado que crianças brasileiras tendem a começar a serem mais precisos em suas avaliações de competência aproximadamente aos 10 anos de idade, ${ }^{14}$ 
enquanto estudos realizados nos Estados Unidos verificam a maior precisão a partir dos 8

anos. ${ }^{18-19}$ A idade mais avançada para atingir a precisão na percepção de competência encontrada nos estudos é relacionada as poucas experiências motoras vivenciadas pela criança e a falta de parâmetros para comparações de competência, tendo em vista que as crianças não comparam suas habilidades motoras com a de outros colegas para se auto avaliar. Essa explicação pode também estar associada a alta percepção de competência dos nossos alunos, tendo em vista que eles reportaram não ter aulas de educação física na escola e nem se envolverem em atividades motoras fora da escola.

\section{CONSIDERAÇÕES FINAIS}

O escasso recurso material foi a maior dificuldade encontrada no início do estágio, o que foi suprido com adaptações de atividades e construções de materiais. Outro aspecto que encontramos dificuldades foi o fato das crianças estarem acostumadas a brincar livremente, sem atividades estruturadas, pois não tinham aulas de educação física na escola. Nesse sentido, foi necessário conversar com as crianças e fazer elas entenderem que nas aulas de educação física existiam regras a serem cumpridas. A construção do protocolo de atitudes aceitáveis nas aulas e as regras juntamente com a turma, facilitou o entendimento dos alunos de que nas aulas, mesmo que com o caráter lúdico, existiam normas a serem seguidas. Além disso, as crianças gostavam das atividades propostas em aula, o que facilitou o a aceitação de atividades estruturadas.

A partir da experiência no estágio com crianças com pouca ou nenhuma experiência em atividades estruturadas percebeu-se a importância dessas atividades para o desenvolvimento motor e cognitivo infantil. Nesse aspecto, os ganhos motores e cognitivos ocorreram rapidamente a partir do momento em que as crianças passam a vivenciar situações e atividades adequadas a faixa etária, ressaltando a importância de aulas de educação física estruturadas desde os anos iniciais do ensino fundamental. Com o decorrer do estágio, as crianças passaram a aceitar cada vez mais as atividades e a se engajar mais nas atividades, o que propiciou o aumento do repertório motor deles, o qual é fundamental para que elas se envolvam em atividades mais complexas futuramente aumentando as 
possibilidades de se tornarem adultos fisicamente ativos. Dessa forma, as crianças passaram a ter prazer nas praticas estruturadas e a valorizar e reconhecer a educação física como disciplina escolar e não como o momento em que eles tem para brincar livremente.

Agradecimentos: Agradecemos ao CNPQ e CAPES pelo fornecimento de bolsas que viabilizaram o estudo.

\section{REFERÊNCIAS}

${ }^{1}$ GALlAHUE, D. L.; OZMUN, J. C. Compreendendo o desenvolvimento motor: bebês, crianças, adolescentes e adultos. São Paulo: Phorte, 2005.

${ }^{2}$ PAYNE, V. G.; ISAACS, L. D. Desenvolvimento motor humano: uma abordagem vitalícia. Rio de Janeiro: Guanabara Koogan, 2007.

${ }^{3}$ VALENTINI, N. C.; TOIGO, A. M. Ensinando educação física nas séries iniciais: desafios e estratégias. Canoas: Unilasalle, 2006.

${ }^{4}$ VALENTINI, N. C. Percepções de competência e desenvolvimento motor de meninos e meninas: um estudo transversal. Movimento, Porto Alegre, v. 8, n. 2, p. 51-62, 2002.

${ }^{5}$ STRONG, W. B. et al. Evidence based physical activity for school-age youth. The Journal of Pediatrics, Saint. Louis, v. 146, n. 6, p. 732-737, 2005.

${ }^{6}$ MCKENZIE, T. L. The preparation of physical educators: a public health perspective. Quest, Champaign, v. 59, p. 346-357, 2007.

${ }^{7}$ SPESSATO; B. C.; GABBARD, C.; VALENTINI, N. C. The role of motor competence and body mass index in children's activity levels in physical education classes. Journal of Teaching in Physical Education, Champaign, v. 32, p. 118-130, 2013. 
${ }^{8}$ WROTNIAK, B. H. et al. The relationship between motor proficiency and physical activity in children. Pediatrics, v. 118, p. 1758-1765, 2006.

${ }^{9}$ SANDERS, S. W. Ativo para a vida: programas de movimento adequados ao desenvolvimento da criança. Porto Alegre: Artmed, 2005.

${ }^{10}$ PALMA, M. S.; PEREIRA, B. O.; VALENTINI, N. C. Guided play and free play in an enriched environment: impact on motor development. Motriz, Rio Claro, v. 20, n. 2, 2014.

${ }^{11}$ SALLIS, J. F.; PROCHASKA, J. J.; TAYLOR, W. C. A review of correlates of physical activity of children and adolescents. Medicine Science in Sports and Exercise, Hagerstown, v. 32, n. 5, p. 963-75, 2000.

${ }^{12}$ HAYWOOD, K. M.; GETCHELL, N. Desenvolvimento motor ao longo da vida. Porto Alegre: Artmed, 2010.

${ }^{13}$ PAPALIA, D. E.; OLDS, S. W.; FELDMAN, R. D. Desenvolvimento humano. São Paulo: McGraw-Hill do Brasil, 2009.

${ }^{14}$ ALMEIDA, G.; VALENTINI, N. C.; BERLEZE, A. Percepções de competência: Um estudo com crianças e adolescentes do ensino fundamental. Movimento, Porto Alegre, v. 15, n. 1, p. 71-97, 2009.

${ }^{15}$ VILLWOCK, G.; VALENTINI, N. C. Percepção de competência atlética, orientação motivacional e competência motora em crianças de escolas públicas: estudo desenvolvimentista e correlacional. Revista Brasileira de Educação Física e Esporte, São Paulo, v. 21, n. 4, p. 245-257, 2007.

${ }^{16}$ STODDEN, D. F. et al. A developmental perspective on the role of motor skill competence in physical. Activity: An emergent relationship. Quest, Champaign, v. 60, p. 290-306, 2008.

Conexões: revista da Faculdade de Educação Física da UNICAMP, Campinas, v. 13, n. 2, p. 206-218, abr./jun. 2015. ISSN: $1983-9030$ 
${ }^{17}$ WEISS, M. R.; AMOROSE, A. J. Children's self-perceptions in the physical domain: Between- and within-age variability in level, accuracy, and sources of perceived competence. Journal of Sport and Exercise Psychology, Champaign, v. 27, p. 226-244, 2005.

${ }^{18}$ HARTER, S. The perceived competence scale for chidren. Children Development, v. 53, n. 1, 1982.

${ }^{19}$ HORN, T. S.; WEISS, M. R. A developmental analysis of children's self-ability judgments in the physical domain. Pediatric Exercise Science, Champaign, v. 3, p. 310326, 1991.

Recebido em: 14 nov. 2015 Aceito em: 19 mar. 2015 Contato: marielesantayana@gmail.com 